\title{
Stem Cell Marker Aldehyde Dehydrogenase 1A1 Expression in Triple-negative Breast Carcinoma
}

\author{
Badawia Bayoumi Ibrahim, Samar Abdel Monem El Sheikh, Mona Salah Abdel Magid, Marwa Abdel Nasser Mohamed* \\ Department of Pathology, Faculty of Medicine, Cairo University, Cairo, Egypt
}

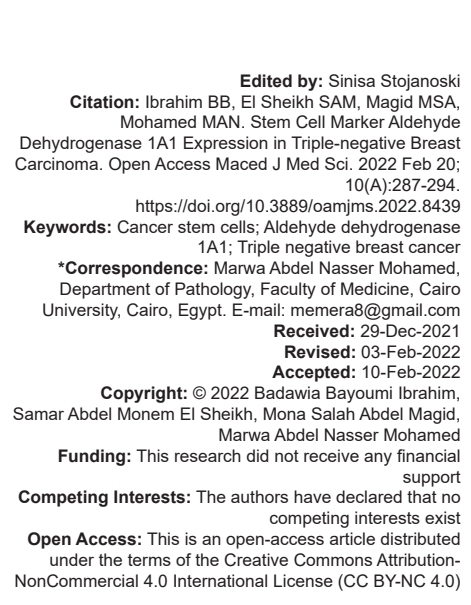

\section{Introduction}

Breast cancer remains a life-threatening disease despite the advanced achievement in breast cancer therapy [2].

Triple-negative breast cancer (TNBC) represents $15 \%$ of all breast cancers in united states and is characterized by the absence of estrogen receptor (ER), progesterone receptor (PR), and human epidermal growth factor receptor-2 (HER2) receptor expression. TNBC is the most aggressive phenotypic subtype of breast cancer [3]. Gene expression profiling analysis often classifies TNBC as a subtype of basal-like breast cancer (BLBC). Approximately, 56\% of TNBC and BLBC gene expression profiles overlap. The overlap ratio can be as high as $60-90 \%$ between TNBC and BLBC, compared to only $11.5 \%$ between non-TNBC and BLBC [4].

Cancer stem cells (CSCs) are a subpopulation of cells within the primary tumor mass, which possess self-renewal, differentiation and potential tumorigenic properties [5].

Aldehyde dehydrogenase 1A1 (ALDH1A1) isozyme oxidizes retinaldehyde to retinoic acid, which regulates the expression of the genes involved in tumor-initiating stem-like cells, thereby initiating tumor growth and resistance to drugs [6].

ALDH1 is the most common BCSC marker and has been studied in both in-vitro and in-vivo BC models [7].

High expression of ALDH1A1 has been reported as a poor prognostic marker in several tumor types and is associated with poor patient outcomes [8].

The aim of the present study is to evaluate immunohistochemical expression of ALDH1A1 in 60 cases of TNBC, then to correlate between expression of ALDH1A1 and other clinicopathological features (Age, tumor size, lymph node status, etc.).

\section{Materials and Methods}

\section{Retrieval of cases}

This is a retrospective study that was carried out on formalin fixed, paraffin embedded tissue blocks of sixty cases of modified radical mastectomy that previously diagnosed as TNBC, retrieved from the 
archives of the Pathology Department, Kasr Al Ainy Hospital, Cairo University during the time period from January 2015 to June 2016.

Data were collected from pathology reports regarding personal data (age and sex), histopathological data (tumor size, grade, nodal metastasis, etc.). Slides stained by ER and PR and HER2/neu state were also collected.

Serial sections of $5 \mu$ thick were prepared from each paraffin block, one of them stained by Hematoxylin and Eosin ( $\mathrm{H}$ and $\mathrm{E})$ for histological evaluation; another one was mounted on a charged slide for immunohistochemical staining by monoclonal antibody against ALDH1A1 antigen. All slides were examined under light microscope.

\section{Histopathologic assessment of cases}

Histopathological examination was done for revision and confirmation of diagnosis.

Tumors were typed according to the criteria described by the World Health Organization (WHO) [9]

Tumor grading was done according to Nottingham grading system [10].

According to the American Joint Committee on Cancer (AJCC) TNM staging system of breast cancer, $8^{\text {th }}$ edition [11].

Presence of ductal carcinoma in situ and specification of its type and its percentage from the tumor bulk.

- $\quad$ Tumor infiltrating lymphocytes (TILs).

- Lymphovascular invasion

- $\quad$ Perineural invasion

Regional lymph node status as regards the absence or presence of metastatic tumor deposits.

Retrieval of immunostained slides of ER and $\mathrm{PR}$ was done. Positive nuclear staining in $\geq 1 \%$ of tumor cells according to ASCO/CAP guidelines recommendations were considered positive [12].

Assessment of Her2/neu state was done according to the criteria in (Table 1) [13].

Table 1: HER2/neu score used to evaluate Hercept Test [13]

\begin{tabular}{ll}
\hline Score & Criteria \\
\hline 0 (Negative) & No immunoreactivity or immunoreactivity in $\leq 10 \%$ of tumor cells. \\
$1+($ Negative $)$ & $\begin{array}{l}\text { Faint weak immunoreactivity in }>10 \% \text { of tumor cells but only a } \\
\text { portion of the membrane is positive (incomplete). }\end{array}$ \\
$2+($ Weak positive) $)$ & $\begin{array}{l}\text { Incomplete and/or weak to moderate complete membrane } \\
\text { immunoreactivity in }>10 \% \text { of tumor cells or intense complete }\end{array}$ \\
& immunoreactivity in $\leq 10 \%$ of tumor cells. \\
$3+$ (Positive) & Moderate to strong complete immunoreactivity in $>10 \%$ of tumor cells. \\
\hline
\end{tabular}

\section{Immunohistochemical assessment of cases}

Immunostaining for ALDH1A1 was performed on all tissue of the biopsies.

Procedure: Sections from paraffin blocks were treated with antigen retrieval solution and then treated with monoclonal antibody for ALDH1A1 [EP1933Y clone, Rabbit IgG, $0.1 \mathrm{ml}$ concentrated, diluted at 1:200 400, manufactured by BIOCARE MEDICAL] using Automated Dako FLEX Ready-to-Use system. DAB was used as a chromogen and hematoxylin as a counter stain. A section of breast cancer (Figure 1) known to be positive for ALDH1A1 was used as positive control.

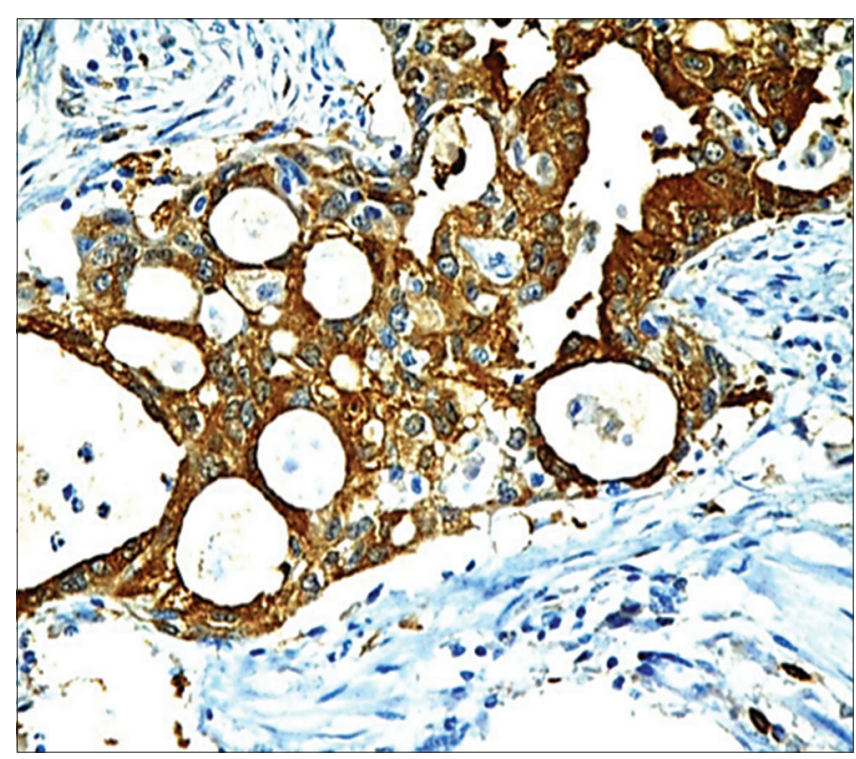

Figure 1: Strong positive expression of ALDH1A1 of invasive duct carcinoma, breast (positive control) (400× original magnification)

\section{ALDH1A1 immunostaining interpretation}

One ALDH1A1 immunostained slide was examined per case. Semi-quantitative analysis of ALDH1A1 immunostaining in tumor cells was performed using Olympus light microscope and the percenting of positively stained cells was recorded in consecutive fields at $\times 400$ magnification.

The cytoplasmic staining of tumors cells was considered positive. The immunoreactivity was evaluated according to;

The staining intensity was scored according to the following scale: 0 score for no signal, 1 score for weak, 2 score for moderate, and 3 score for strong staining.

The percentage of cells with positive staining for the ALDH1A1 antibody was quantized (from undetectable level or $0 \%$, to homogeneous staining or $100 \%)$.

Results were scored by multiplying the percentage of positive cells by intensity score by so called Quick score $(Q)(Q=P x l ;$ Maximum $=300$. Due to the relatively large number of positive cases, a statistical analysis was performed with a negative (score $\leq 10$ ) and positive (score >10) cutoff [1].

All data were collected and tabulated;ALDH1A1 expression and the other clinicopathological variables were correlated with each other and statistical analysis were performed to detect any significant correlation. 


\section{Classification of breast cancer cases}

All cases were molecularly classified as TNBC. TNBC was defined as ER, PR and HER2/neu negative by immunohistochemistry.

\section{Statistical analysis}

All collected data were revised for completeness and consistency. Pre-coded data were entered on the computer using "Microsoft Office Excel Software" program (2013) for windows. Data were then transferred to the Statistical Package of Social Science Software program, version 24 (SPSS) to be statistically analyzed.

Data were summarized using mean, and standard deviation for quantitative variables and frequency and percentage for qualitative ones. Comparison between groups was performed using independent sample t-test or one-way ANOVA with post hoc Tukey's test for quantitative variables and Chisquare or Fisher's exact test for qualitative ones.

$p<0.05$ were considered statistically significant and $<0.01$ were considered highly significant. Graphs were used to illustrate some information.

\section{Results}

This retrospective study was conducted on 60 cases of TNBC. Their ages ranged from 22 to 72 years with a mean age of 50.08 years. Thirty-five cases were 50 years or less $(58.3 \%)$ and 25 cases were older than 50 years $(41.7 \%)$.

The tumor size ranged from 1.5 to $9 \mathrm{~cm}$ with the mean size of $5.18 \mathrm{~cm} .52$ cases were found to be T2 $(86.7 \%), 5$ cases were T3 $(8.3 \%)$, and 3 cases were T1 (5\%).

About 53 cases (88.3\%) are classified histologically as invasive ductal carcinoma (IDC), four cases $(6.7 \%)$ were of lobular pattern $(6.7 \%)$ and three cases $(5 \%)$ displayed mixed duct and lobular pattern.

As regards to the degree of differentiation, $52(86.7 \%)$ of cases were moderately differentiated (grade II) and 8 (13.3\%) were poorly differentiated (grade III). The high-grade tumors included 5 cases of invasive duct carcinoma (no special type [NST]), 2 cases of lobular and one case of mixed pattern. $39(65 \%)$ of cases showed no intraductal in situ components and $21(35 \%)$ of cases showed intraductal in situ changes with 17 cases of minor components and 4 cases of major component. In the studied cases, 50 (83.3\%) of cases showed TILs $\leq 50 \%$ and $10(16.7 \%)$ showed TILs $>50 \% .57(95 \%)$ of cases were negative for Lymphovascular invasion and only $3(5 \%)$ of cases showed Lymphovascular invasion carcinomas, all studied cases were negative for perineural invasion. Most of the studied cases revealed lymph nodes metastatic deposits; $16(26.7 \%)$ of $(\mathrm{N} 1), 25(41.7 \%)$ of $\mathrm{N} 2$, and $4(6.6 \%)$ of (N3) while $15(25 \%)$ of cases were negative for lymph node metastasis. As regards AJCCTNM stage grouping, stage III was the dominant stage; 31 cases (51.67\%) followed by Stage II; 26 cases $(43.33 \%)$ then stage I; 3 cases (5\%).

Immunohistochemical assessment of ALDH1A1 expression revealed Fifty-three cases (88.3\%) showed positive ALDH1A1 expression while 7 cases $(11.7 \%)$ were negative for ALDH1A1 expression (Figures 2-9).

Statistical analysis revealed no statistically significant correlations between ALDH1A1 expression and other clinicopathological parameters (Table 2).

Table 2: Correlations between ALDH1A1 expression and clinicopathological data of the studied TNBC cases

\begin{tabular}{|c|c|c|c|c|}
\hline \multirow[t]{2}{*}{ Clinicopathological Variable } & \multicolumn{2}{|c|}{ ALDH1A1 Expression } & \multirow[t]{2}{*}{ Total } & \multirow[t]{2}{*}{$\mathrm{p}$-value } \\
\hline & Positive & Negative & & \\
\hline \multicolumn{5}{|l|}{ Age } \\
\hline$\leq 50$ & $30(85.7 \%)$ & $5(14.3 \%)$ & $35(58 \%)$ & \multirow[t]{2}{*}{0.455} \\
\hline$>50$ & $23(92 \%)$ & $2(8 \%)$ & $25(42 \%)$ & \\
\hline \multicolumn{5}{|l|}{ Tumor size $(\mathrm{cm})$} \\
\hline $\mathrm{T} 1(\leq 2 \mathrm{~cm})$ & $3(100 \%)$ & $0(0.0 \%)$ & $3(5 \%)$ & \multirow[t]{3}{*}{0.544} \\
\hline $\mathrm{T} 2(>2 \mathrm{~cm}-5 \mathrm{~cm})$ & $45(86.5 \%)$ & $7(13.5 \%)$ & $52(86.7 \%)$ & \\
\hline T3 $(>5 \mathrm{~cm})$ & $5(100 \%)$ & $0(0.0 \%)$ & $5(8.3 \%)$ & \\
\hline \multicolumn{5}{|l|}{ Histological subtypes } \\
\hline IDC & $47(88.7 \%)$ & $6(11.3 \%)$ & $53(88.3 \%)$ & \multirow[t]{3}{*}{0.387} \\
\hline Lobular carcinoma & $4(100 \%)$ & $0(0.0 \%)$ & $4(6.7 \%)$ & \\
\hline Mixed & $2(66.7 \%)$ & $1(33.3 \%)$ & $3(5 \%)$ & \\
\hline \multicolumn{5}{|l|}{ Tumor grade } \\
\hline Grade II & $46(88.5 \%)$ & $6(11.5 \%)$ & $52(86.7 \%)$ & \multirow[t]{2}{*}{0.937} \\
\hline Grade III & $7(87.5 \%)$ & $1(12.5 \%)$ & $8(13.3 \%)$ & \\
\hline \multicolumn{5}{|l|}{ DCIS } \\
\hline No & $34(87.2 \%)$ & $5(12.8 \%)$ & $39(65 \%)$ & \multirow[t]{2}{*}{0.704} \\
\hline Yes & $19(90.5 \%)$ & $2(9.5 \%)$ & $21(35 \%)$ & \\
\hline \multicolumn{5}{|l|}{ TILs } \\
\hline$\leq 50$ & $45(90.0 \%)$ & $5(10.0 \%)$ & 50 (83.3\%) & \multirow[t]{2}{*}{0.369} \\
\hline$>50$ & $8(80.0 \%)$ & $2(20.0 \%)$ & $10(16.7 \%)$ & \\
\hline \multicolumn{5}{|l|}{ LVI } \\
\hline No & $50(87.7 \%)$ & $7(12.3 \%)$ & $57(95.0 \%)$ & \multirow[t]{2}{*}{0.518} \\
\hline Yes & $3(100.0 \%)$ & $0(0.0 \%)$ & $3(5 \%)$ & \\
\hline \multicolumn{5}{|l|}{ Lymph node stage } \\
\hline No & $14(93.3 \%)$ & $1(6.7 \%)$ & $15(25 \%)$ & \multirow[t]{4}{*}{0.715} \\
\hline N1 & $14(87.5 \%)$ & $2(12.5 \%)$ & $16(26.7 \%)$ & \\
\hline N2 & $21(84.0 \%)$ & $4(16.0 \%)$ & $25(41.7 \%)$ & \\
\hline N3 & $4(100.0 \%)$ & $0(0.0 \%)$ & $4(6.7 \%)$ & \\
\hline \multicolumn{5}{|l|}{ TNM stage grouping } \\
\hline Stage I & $3(100.0 \%)$ & $0(0.0 \%)$ & $3(5 \%)$ & \multirow[t]{3}{*}{0.801} \\
\hline Stage II & $23(88.5 \%)$ & $3(11.5 \%)$ & $26(43.33 \%)$ & \\
\hline Stage III & $27(87.1 \%)$ & $4(12.9 \%)$ & $31(51.67 \%)$ & \\
\hline
\end{tabular}

\section{Discussion}

TNBC is a breast cancer subtype that is characterized by poor prognosis and aggressive behavior. Meanwhile, CSCs are believed to contribute to tumorigenesis and metastasis.

Since the first report by Ginestier et al. [14] showing that ALDH1A1 expression was associated with poor clinical outcome in breast cancer, several studies have indicated that ALDH1A1+ breast cancer cells are related to TNBCs. 
In the present study, we further analyzed the relationship between CSCs and cancer development in TNBC patients using ALDH1A1 as a CSC marker and correlated the immunohistochemical staining of ALDH1A1 stem cell marker with the clinicopathological characteristics of breast cancer in a random sample of Egyptian females.

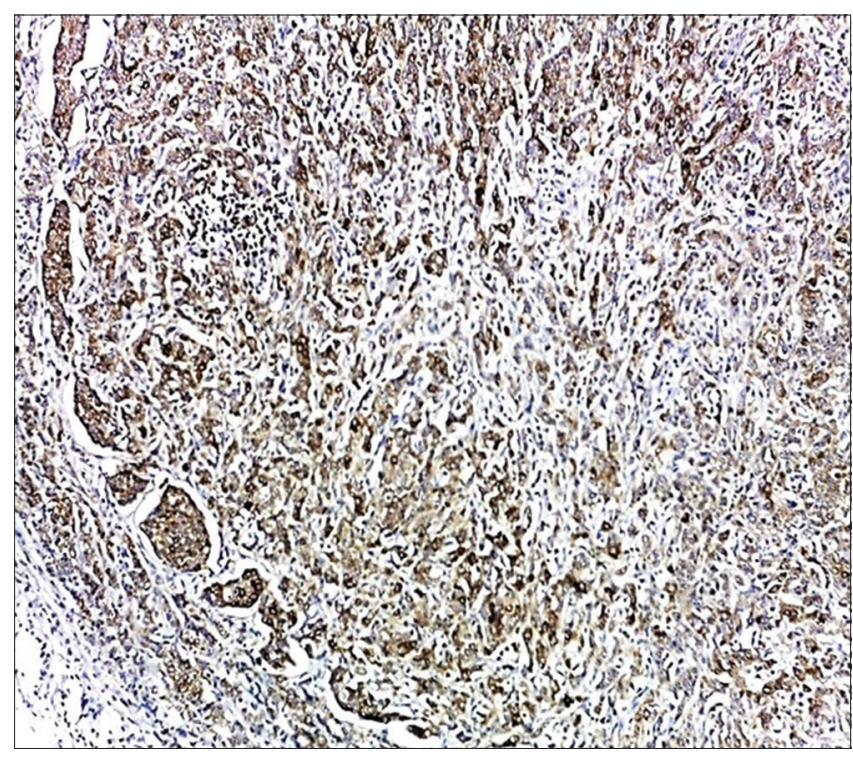

Figure 2: Strong Expression of ALDH1A1 in Invasive Duct Carcinoma Grade II (200× original magnification)

The present study included 60 cases of TNBC. The ages of the patients ranged from 22-72 with a mean age of 50.08 with $58.3 \%$ of patients were $\leq 50$ years.

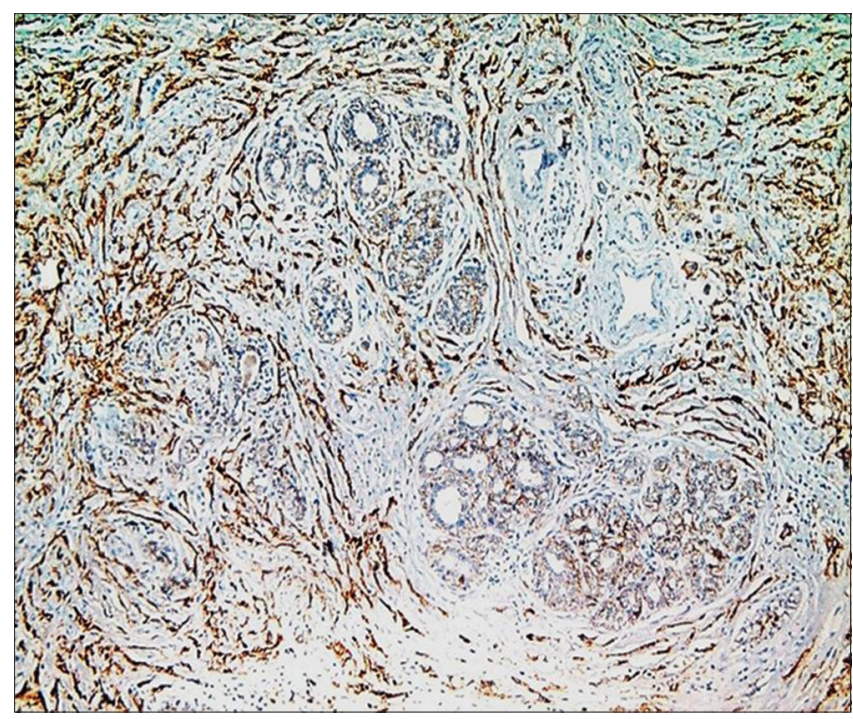

Figure 3: Strong Expression of ALDH1A1 in Invasive Lobular Carcinoma Grade II (200× original magnification)

The tumor size in this study ranged from 1.5 to $9 \mathrm{~cm}$ with the mean size of $5.18 \mathrm{~cm}$. T2 was the dominant size (52 cases representing $86.7 \%$ ), while 5 cases were T3 (representing 8.3\%) and 3 cases were T1 (representing 5\%). Rhakha et al. [15] stated that the majority of their TNBC cases presented at T2 and attributed the large tumor size to the rapid growth of these tumors. However, in

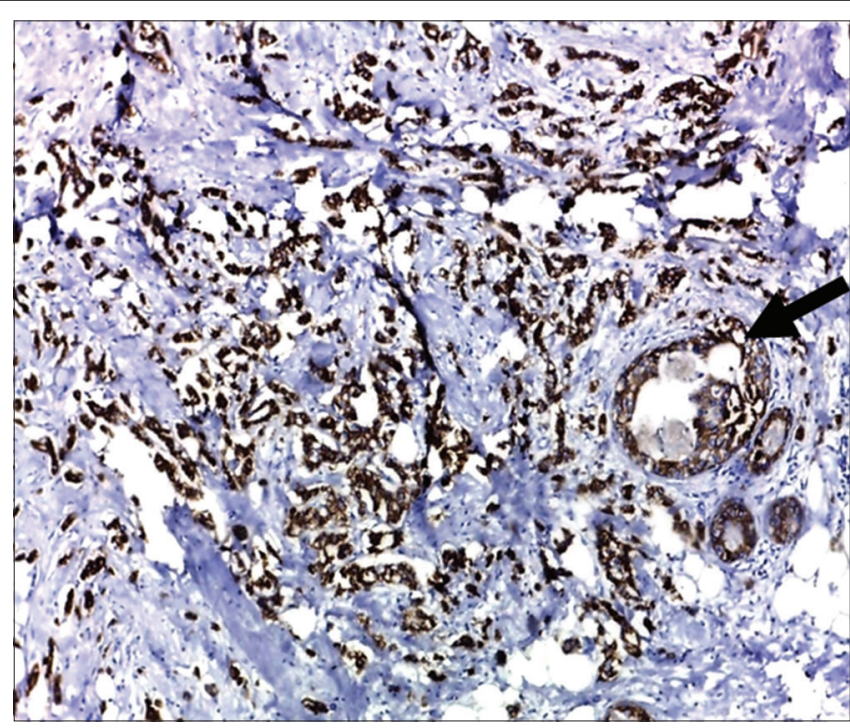

Figure 4: Strong Expression of ALDH1A1 in invasive duct carcinoma with intraductal component (arrow) (200× original magnification)

a study by Rebecca et al. [16], $66 \%$ of the TNBC cases were T3.

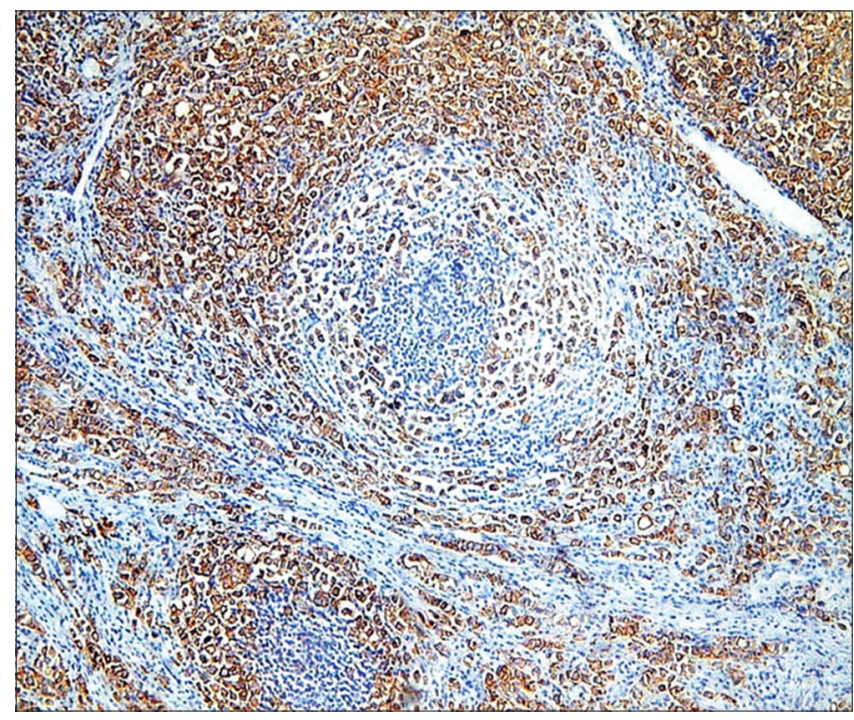

Figure 5: Strong Expression of ALDH1A1 in Metastatic lymph node by Invasive duct carcinoma (200× original magnification)

From a histologic standpoint, invasive duct carcinoma (NST) was the predominant subtype in this study and accounted for nearly $88 \%$ of all cases. As for the other variants in this present study, lobular carcinoma represented about $7 \%$ and mixed type represented $5 \%$. This finding is in concordance with the published study of Bianchini et al. [3] which denoted that $95 \%$ of the TNBC cases are of invasive duct carcinoma (NST) histological type; another breast cancer comparative study by Thike et al. [17] stated that IDC (NOS) represented $77 \%$, the medullary carcinoma cases represented $6 \%$, and lobular carcinoma cases represented $2.4 \%$. Interestingly, Thike et al. [17] postulated that prognosis in each of these appears to be distinct despite sharing the triple-negative phenotype.

When analyzing the tumor grade in this study, 52 cases were grade II, constituting (86.7\%) 


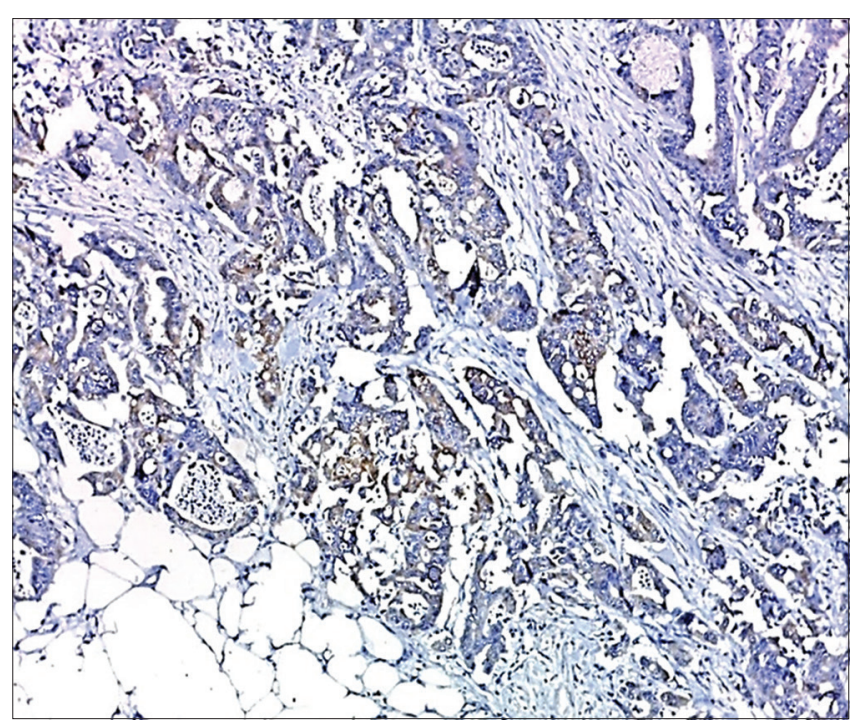

Figure 6: Moderate Expression of ALDH1A1 in Invasive Duct Carcinoma Grade II (200× original magnification)

of the cases, and 8 cases were grade III (13.3\%). Thus, all the cases included in this study were high grade (none of the cases were grade I). This agreed with Nassar et al. [18] who found that the majority $(77 \%)$ of their triple negative cases were high grade. The higher grade involved in this study may be attributed to the later presentation of breast cancer among Egyptian patients together with genetic variability.

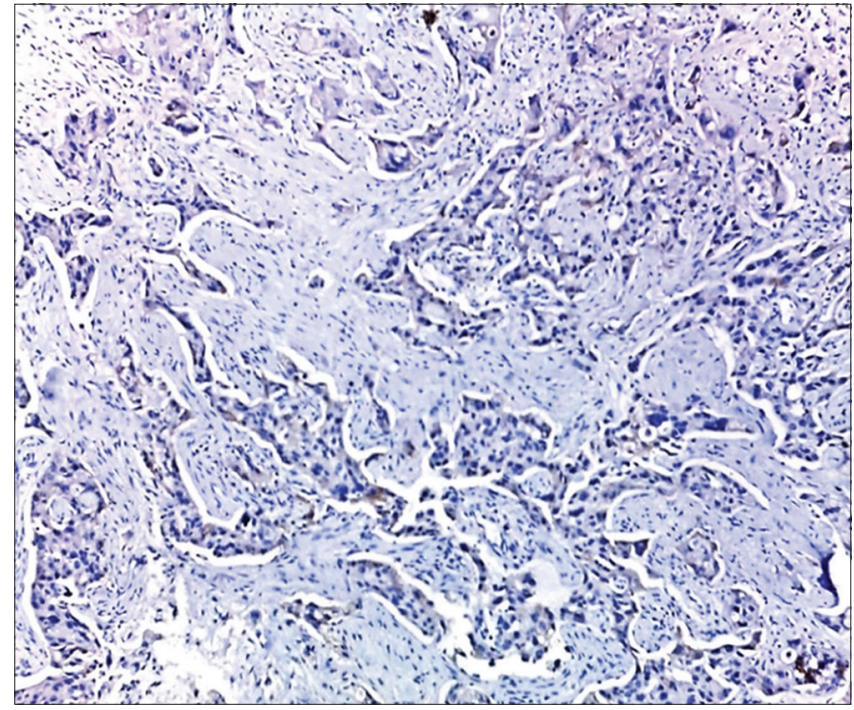

Figure 7: Weak Expression of ALDH1A1 in Invasive Duct Carcinoma Grade II (200x original magnification)

Wen et al. [19] showed in a retrospective case study that high histologic grade was more commonly observed in triple-negative breast tumors (68.1\%) than in luminal breast tumors $(23.5 \%)$. High mitotic count and high nuclear pleomorphism were also more prevalent in TNBC, as $44.7 \%$ and $78.7 \%$, respectively. In the study done by Hegmane et al. [20], no grade I was detected as a finding similar to our study, in contrast, grade III constituted $71 \%$, grade II comprised $25 \%$ and $4 \%$ were not graded. This discrepancy in

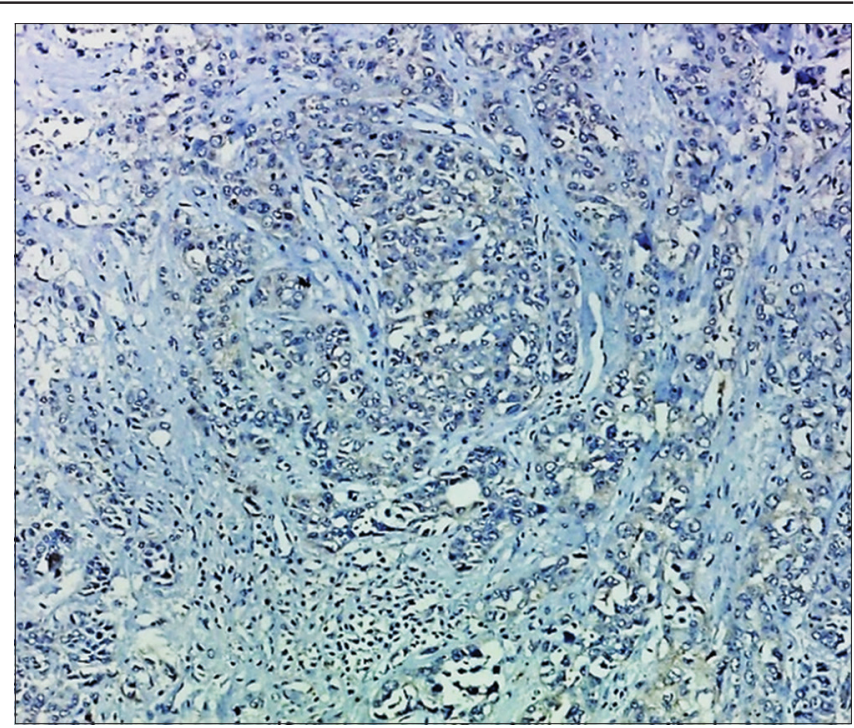

Figure 8: Weak Expression of ALDH1A1 in Invasive Duct Carcinoma Grade III (200× original magnification)

grade II and III may be due to subjective evaluation in grading system.

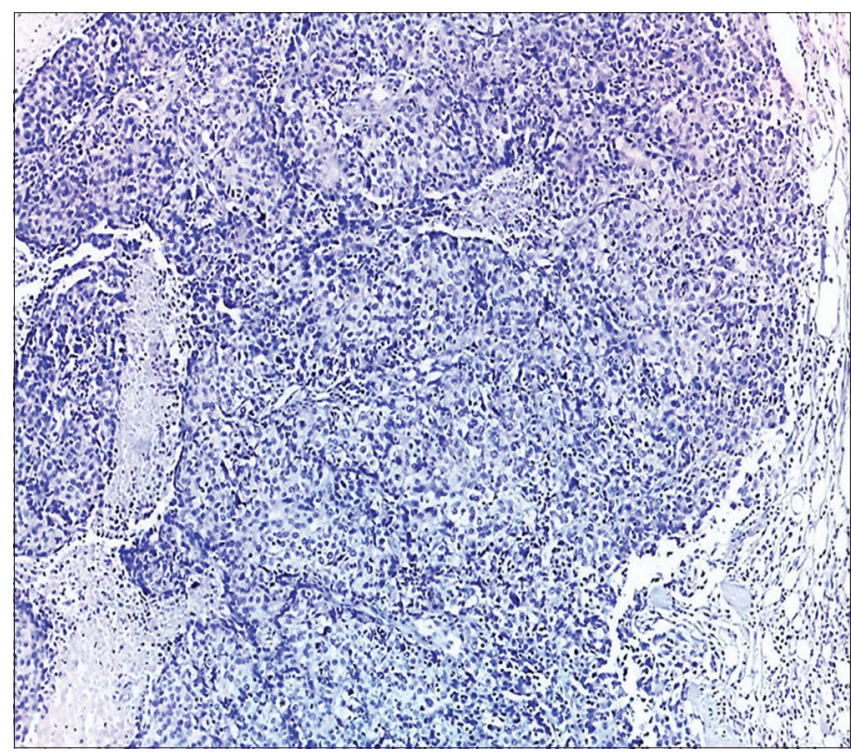

Figure 9: Negative Expression of ALDH1A1 in Invasive Duct Carcinoma Grade II (200× original magnification)

It is widely believed that breast cancer initiates as the pre-malignant stage of atypical ductal hyperplasia, progresses into the pre-invasive stage of DCIS, and culminates in IDC. In this study, in situ component was evident in 21 cases (35\%). This percentage was much lower in a triple negative study performed in Japan where only $30 \%$ of a 97 -case study showed intraductal component [21]

Tumors that have more than $50 \%$ lymphocytic infiltrate are called lymphocyte-predominant breast cancer (LPBC) and have the best prognosis [22]. In our study, the percentage of LPBC represented $16.7 \%$ of total cases. A retrospective study of 897 TNBC patients showed a median percentage of $20 \%$ TILs and $21.9 \%$ LPBC [23].

Regarding Lymphovascular invasion, only 3 cases $(5 \%)$ out of sixty studied cases showed 
Lymphovascular invasion. These results are quite different from those reported by Agarwal et al. [24]

Regarding metastatic tumor deposits to regional lymph nodes, 45 cases $(75 \%)$ out of the studied sixty cases showed positive axillary lymph node metastatic deposits with the following distribution; N1: 16 cases $(26.7 \%), N 2$ : 25 cases $(41.7 \%)$, and N3: 4 cases $(6.6 \%)$.

Interestingly, the majority of TNBCs in the study by $\mathrm{Na}$ et al. [25] had metastatic deposits in 1-3 axillary lymph nodes (N1; 45.5\%). Yet, the remaining cases in that study showed close results to this study; N2: $34.5 \%$ and N3: $10 \%$. Other studies reported higher incidence of nodal metastasis as mentioned by Hegmane et al. [20] who reported nodal metastasis in $94 \%$.

According to AJCC TNM stage grouping, stage III was the dominant stage Thirty-one cases, constituting $(51.67 \%)$ of the cases, and only 3 cases were stage I (5\%) these agreed with Atwa et al. [26] who found that $60 \%$ of the patients with stage III. These results are quite different from those reported by Edvin et al. [27] stated that the majority of their TNBC cases with stage II.

ALDH1A1 may be used as biomarker to identify breast CSC groups and is correlated with the malignant transformation of breast tissue and progression into a more aggressive triple-negative phenotype [28].

Evaluation of the results of immunostaining for ALDH1A1 in the present study showed that only 7 cases $(11.7 \%$ of total cases) were negative for immunoreactivity. The remaining 53 cases $(88.3 \%$ of total cases) showed positive cytoplasmic reactivity.

In the present study, positive ALDH1A1 expression was observed in $88.3 \%$ of patients. This is supported by the work of Madjd et al. [29] who found expression of ALDH $1 \mathrm{~A} 1$ in $74 \%$ of cases. Atwa et al. [26] found ALDH1A1 expression in $66.6 \%$ of the patients and ALDH1A1 was expressed in both epithelial tumor cells and stromal cells. Interestingly, in study done by Fei et al. [30], a majority of the ALDH1A1+ cases showed low levels of ALDH1A1 expression that presented as focal positive expression, which may be compatible with the idea that CSCss represent only a minority of the tumor cell population. These differences may be attributed to different scoring methods used by the authors.

A rising prevalence of ALDH1A1 expression with increasing age; most patients over 50 years representing $92 \%$ was observed in this study; however, no significant correlation was detected between ALDH1A1 and age $(p=0.455)$; this is in agreement with several studies conducted by Resetkova et al. [31] and Hosni et al. [32].

Regarding tumor size, there was no significant positive correlation between ALDH1A1 expression and tumor size $(p=0.544)$, which is similar to the findings of Madjd et al. [29]. However, these findings are in disagreement with results of Atwa et al. [26] who reported significant positive correlation between ALDH1A1 expression and tumor size. These outcome differences may be a result of varying sample sizes.

As for the correlation of the ALDH1A1 staining results to the histopathological variables, $88.7 \%$ of patients with IDC (NST) showed positive immunostaining. In the study done by Huihui et al. [33], ALDH1A1 was positive in 22 of 85 cases $(25.9 \%)$ of IDC.

Fei et al. [30] found ALDH1A1 was positive in 87 of 152 cases $(57 \%)$ of IDC and 4 of 31 cases $(13 \%)$ of invasive lobular carcinomas and 1 of 6 cases $(16.7 \%)$ of other histologic types.

Hosni et al. [32] found ALDH1A1 was positive in 8 of 24 cases (33.3\%) of IDC and 1 of 3 cases $(33.3 \%)$ of invasive lobular carcinomas.

Regarding the relation between tumor grade and ALDH1A1 expression, $88.5 \%$ of grade II tumors and $87.5 \%$ of grade III tumors showed positive immunostaining; however, no significant correlation was seen ( $p=0.937)$. Ohi et al. [34] showed that ALDH1A1 expression in carcinoma cells was correlated only with high histological grade $(P<0.006)$ and therefore suggest that ALDH1A1 expression in carcinoma cells is an independent prognostic factor in TN breast cancer patients. This was different from other studies conducted by Hosni et al. [32]; Atwa et al. [26] and Fei et al. [30].

The TNBC cases in this study that had intraductal components accounted for $35 \%$ of the total cases and $90.5 \%$ of these tumors showed positive immunostaining for ALDH1A1. Yet, statistical analysis between ALDH1A1 expression and presence of intraductal components showed no significant correlation. With a similar standpoint, Kurbel [35] proved in a comparative study between TNBCs and non-TNBCs that intraductal components are more evident in luminal invasive cancers and that suggested that the quick tumor progression might be the main feature of the triple-negative breast tumors, leading to less intraductal evidence at the time of breast cancer diagnosis.

The present study revealed non-significant correlation between positive ALDH1A1 expression and other prognostic clinicopathological parameters; Lymphovascular invasion and TILs.

A non-significant correlation was detected between ALDH1A1 expression and nodal status in which ALDH1A1 expression was seen in $88.3 \%$ of the total cases $(p=0.715)$. Thaer et al. [36] stated that tumors with positive lymph nodes expressed ALDH1A1 more frequently than did node-negative tumors $(p=0.006)$. 
Regarding the relation between AJCC TNM stage grouping and ALDH1A1 expression, $88.5 \%$ of Stage II tumors and $87.1 \%$ of stage III tumors showed positive immunostaining; however, no significant correlation was seen $(p=0.801)$. This in agreement with other studies conducted by Edvin et al. [27] and Atwa et al. [26].

Fei et al. [30] found that the expression of ALDH1A1 protein evaluated by immunohistochemistry staining in tumor cells significantly correlated with larger tumor size $(p=0.02)$ and advanced stage $(p=0.04)$.

Liu et al. [37] examined 15 publications and found that ALDH1A1 expression with large tumor size, higher histological grade, later stage, higher HER2 expression, and lower ER expression.

\section{Conclusion}

In conclusion, the level of ALDH1A1 expression was relatively high in the majority of TNBCs with different staining percentages and intensities as most studies stated. There is no statistical significance between ALDH1A1 expression and other prognostic clinicopathological parameters; age, size, tumor grade, histologic subtypes, lymphovascular invasion, intraductal components, TILs, and TNM stage grouping. Documented statistics for TNBC in Egypt as well as its subsets are recommended to identify their incidence and risk factors.

\section{Ethical Committee}

The project is approved by ethical committee of faculty of medicine, Cairo university.

\section{Acknowledgments}

I l'd like to thank my research supervisors, for their patient instruction, passionate support, and constructive criticisms of this study effort. I'm most thankful for the pathology Department, Faculty of Medicine Cairo University for support.

\section{References}

1. Ma F, Li H, Li Y, Ding X, Wang H, Fan Y, et al. Aldehyde dehydrogenase 1 (ALDH1) expression is an independent prognostic factor in triple negative breast cancer (TNBC). Medicine (Baltimore). 2017;96(14):e6561. https://doi. org/10.1097/MD.0000000000006561

PMid:28383433

2. Butti R, Gunasekaran VP, Kumar TV, Banerjee P, Kundu GC Breast cancer stem cells: Biology and therapeutic implications. Int J Biochem Cell Biol. 2019;107:38-52. https://doi. org/10.1016/j.biocel.2018.12.001 PMid:30529656

3. Bianchini G, Balko JM, Mayer IA, Sanders ME, Gianni L. Triple-negative breast cancer: Challenges and opportunities of a heterogeneous disease. Nat Rev Clin Oncol. 2016;13(11):674-90. https://doi.org/10.1038/nrclinonc.2016.66 PMid:27184417

4. Prat A, Pineda E, Adamo B, Galván P, Fernández A, Gaba L, et al. Clinical implications of the intrinsic molecular subtypes of breast cancer. Breast. 2015;24 Suppl 2:S26-35. https://doi. org/10.1016/j.breast.2015.07.008

PMid:26253814

5. Pires BR, De Amorim IS, Souza LD, Rodrigues JA, Mencalha AL. Targeting cellular signaling pathways in breast cancer stem cells and its implication for cancer treatment. Anticancer Res. 2016;36(11):5681-91. https://doi.org/10.21873/ anticanres. 11151

PMid:27793889

6. Vassalli G. Aldehyde dehydrogenases: Not just markers, but functional regulators of stem cells. Stem Cells Int. 2019;2019;3904645. https://doi.org/10.1155/2019/3904645 PMid:30733805

7. Martinez-Cruzado L, Tornin J, Santos L, Rodriguez A, GarcíaCastro J, Morís F, et al. Aldh1 expression and activity increase during tumor evolution in sarcoma cancer stem cell populations. Sci Rep. 2016;6:27878. https://doi.org/10.1038/srep27878 PMid:27292183

8. Yang W, Wang Y, Wang W, Chen Z, Bai G. Expression of aldehyde dehydrogenase $1 \mathrm{~A} 1$ (ALDH1A1) as a prognostic biomarker in colorectal cancer using immunohistochemistry. Med Sci Monit. 2018;24:2864-72. https://doi.org/10.12659/ MSM.910109

PMid:29748529

9. Tan $\mathrm{PH}$, Ellis I, Allison K, Brogi E, Fox SB, Lakhani $\mathrm{S}$, et al. The 2019 World Health Organization classification of tumours of the breast. Histopathology. 2020;77(2):181-5. https://doi. org/10.1111/his.14091

PMid:32056259

10. Mei F, Liu JY, Xue WC. Histopathological grading of invasive breast carcinoma: Nottingham histopathological grading system. Chin J Pathol. 2019;48(8):659-64.

11. Giuliano AE, Edge SB, Hortobagyi GN. Eighth edition of the AJCC cancer staging manual: Breast cancer. Ann Surg Oncol. 2018;25(7):1783-5. https://doi.org/10.1245/s10434-018-6486-6 PMid:29671136

12. Hammond ME, Hayes DF, Dowsett M, Allred DC, Hagerty KL, Badve $\mathrm{S}$, et al. American society of clinical oncology/college of American pathologists guideline recommendations for immunohistochemical testing of estrogen and progesterone receptors in breast cancer (unabridged version). Arch Pathol Lab Med. 2010;134(7):e48-72. https://doi.org/10.5858/134.7.e48 PMid:20586616

13. Wolff AC, Hammond ME, Hayes DF. Re: Predictability of adjuvant trastuzumab benefit in N9831 patients using the ASCO/CAP HER2-positivity criteria. J Natl Cancer Inst. 2012;104(12):957-8. https://doi.org/10.1093/jnci/djs243

PMid:22581974 
14. Ginestier C, Charafe-Jauffret E, Bertucci F, Eisinger F, Geneix J, Bechlian D, et al. Distinct and complementary information provided by use of tissue and DNA microarrays in the study of breast tumor markers. Am J Pathol. 2002;161(4):1223-33. https://doi.org/10.1016/S0002-9440(10)64399-4 PMid:12368196

15. Rakha E, El-Sayed M, Green A, Lee A, Robertson JF, Ellis IO Prognostic markers in triple negative breast cancer. Cancer. 2007;109(1):25-32. https://doi.org/10.1002/cncr.22381 PMid: 17146782

16. Rebecca D, Maureen T, Kathleen P, Hanna WM, Kahn HK, Sawka CA, et al. Triple-negative breast cancer: Clinical features and patterns of recurrence. Clin CancerRes. 2007;13(15):4429-34. https://doi.org/10.1158/1078-0432.CCR-06-3045 PMid:17671126

17. Thike AA, Cheok PY, Jara-Lazaro AR, Tan B, Tan P, Tan PH. Triple negative breast cancer: Clinicopathological characteristics and relationship with basal-like breast cancer. Mod Pathol. 2010;23(1):123-33. https://doi.org/10.1038/ modpathol.2009.145

PMid:19855377

18. Nassar A, Sookhan N, Santisteban M, Bryant SC, Boughey JC, Giorgadze $\mathrm{T}$, et al. Diagnostic utility of snail in metaplastic breast carcinoma. Diagn Pathol. 2010;5:76. https://doi. org/10.1186/1746-1596-5-76 PMid:21110878

19. Kuo WH, Chang YY, Lai LC, Tsai MH, Hsiao CK, Chang KJ, et al. Molecular characteristics and metastasis predictor genes of triple-negative breast cancer: A clinical study of triple-negative breast carcinomas. PLoS One. 2012;7(9):e45831. https://doi. org/10.1371/journal.pone.0045831

\section{PMid:23049873}

20. Hegmane A, Liepniece-Karele I. Response to neoadjuvant therapy and long-term outcome in patients with triple negative breast cancer. Eur Sci J. 2014;10(12):1857-7881.

21. Ishikawa $Y$, Horiguchi J, Toya $H$, Nakajima $H$, Hayashi $M$, Tagaya $\mathrm{N}$, et al. Triple-negative breast cancer: Histological subtypes and immunohistochemical and clinicopathological features. Sci J. 2011;102(3):656-62. https://doi.org/10.111 1/j.1349-7006.2011.01858

22. Disis ML and Stanton SE. Triple-Negative Breast Cancer: Immune Modulation as the New Treatment Paradigm. Virginia, United States: ASCO Educational Book; 2015.

23. Pruneri G, Vingiani A, Bagnardi $V$, Rotmensz N, De Rose A, Palazzo A, et al. Clinical validity of tumor-infiltrating lymphocytes analysis in patients with triple negative breast cancer. Ann Oncol. Ann Oncol. 2016;27(2):249-56. https://doi.org/10.1093/ annonc/mdv571 PMid:26598540

24. Agarwal G, Nanda G, Lal P, Mishra A, Agarwal A, Agrawal V, et al. Outcomes of triple-negative breast cancers (TNBC) compared with non-TNBC: Does the survival vary for all stages? World J Surg. 2016;40(6):1362-72. https://doi.org/10.1007/ s00268-016-3422-4

PMid:26842691

25. Yuan N, Meng M, Liu C, Feng L, Hou L, Ning Q, et al. Clinical characteristics and prognostic analysis of triple-negative breast cancer patients. Mol Clin Oncol. 2014;2(2):245-51. https://doi. org/10.3892/mco.2013.230

PMid:24649341
26. Atwa HA, Ibrahim HM, Ismail El, Ibrahim IM. ALDH $1 \mathrm{~A} 1$ and caveolin-1 expression in triple negative breast cancer. Oncol Transl Med. 2017;3:185-96. https://doi.org/10.1007/ s10330-017-0231-1

27. Murrja E, Turna ZH, Ozturk MA, Cinkaya A, Ozturk T. Aldehyde dehydrogenase-1 expression and prognosis in triple-negative breast cancer. Med Sci Discov. 2014;1(2):44. https://doi. org/10.17546/msd.82203

28. Kunju LP, Cookingham C, Toy KA, Chen W, Sabel MS, Kleer CG. EZH2 and ALDH-1-mark breast epithelium at risk for breast cancer development. Mod Pathol. 2011;24(6):786-93. https:// doi.org/10.1038/modpathol.2011.8.

PMid:21399615

29. Madjd Z, Ramezani B, Molanae S, Asadi-Lari M. High expression of stem cell marker ALDH1 is associated with reduced BRCA1 in invasive breast carcinomas. Asian Pac J Cancer Prev. 2012;13(6):2973-8. https://doi.org/10.7314/ apjcp.2012.13.6.2973 PMid:22938492

30. Ma F, Li H, Wang H, Shi X, Fan Y, Ding $X$, et al. Enriched CD44+/CD24-population drives the aggressive phenotypes presented in triple-negative breast cancer (TNBC). Cancer Lett. 2014;353(2):153-9. https://doi.org/10.1016/j.canlet.2014.06.022 PMid:25130168

31. Resetkova E, Reis-Filho JS, Jain RK, Mehta R, Thorat MA, Nakshatri $\mathrm{H}$, et al. Prognostic impact of ALDH1 in breast cancer: A story of stem cells and tumor microenvironment. Breast Cancer Res Treat. 2010;123(1):97-108. https://doi.org/10.1007/ s10549-009-0619-3

PMid:19911270

32. Hosni H, Daoud S, Bassam A. Immunohistochemical study of stem cell marker ALDH $1 \mathrm{~A} 1$ and BRCA1 in breast cancer. Acad J Cancer Res 2014;7:1-7.

33. Li H, Ma F, Wang $\mathrm{H}$, Lin $\mathrm{C}$, Fan $\mathrm{Y}$, Zhang $\mathrm{X}$, et al. Stem cell marker aldehyde dehydrogenase 1 (ALDH1)-expressing cells are enriched in triple-negative breast cancer. Int J Biol Markers. 2013;28(4):e357-64. https://doi.org/10.5301/jbm.5000048 PMid:24338721

34. Ohi Y, Umekita Y, Yoshioka T, Souda M, Rai Y, Sagara Y, et al. Aldehyde dehydrogenase 1 expression predicts poor prognosis in triple-negative breast cancer. Histopathology. 2011;59(4):776-80. https://doi.org/10.1111/j.1365-2559.2011.03884.x PMid:22014057

35. Kurbel S. In search of triple-negative DCIS: Tumor-type dependent model of breast cancer progression from DCIS to the invasive cancer. Tumour Biol. 2013;34(1):1-7. https://doi. org/10.1007/s13277-012-0602-1 PMid:23208673

36. Khoury T, Ademuyiwa FO, Chandrasekhar R, Jabbour $M$, Deleo A, Ferrone $\mathrm{S}$, et al. Aldehyde dehdrogenase 1A1 expression in breast cancer is associated with stage, triple negativity, and outcome to neoadjuvant chemotherapy. Mod Pathol. 2012;25(3):388-97. https://doi.org/10.1038/ modpathol.2011.172 PMid:22080062

37. Liu Y, Lv DL, Duan JJ, Xu SL, Zhang JF, Yang XJ, et al ALDH1A1 expression correlates with clinicopathologic features and poor prognosis of breast cancer patients: A systematic review and meta-analysis. BMC Cancer. 2014;14:444. https:// doi.org/10.1186/1471-2407-14-444

PMid:24938375 